\title{
Francisco Acuyo en portugués. Cuatro poemas para una antología
}

\author{
(Francisco Acuyo in Portuguese. Four poems for an anthology)
}

José ANTONIO SABIO PINILLA

(Universidad de Granada)

\author{
Fecha de recepción: 15 de febrero de 2010 \\ Fecha de aceptación: 15 de marzo de 2010
}

Resumen: En este artículo se da a conocer el proyecto de traducción al portugués de una antología de la poesía del poeta Francisco Acuyo. Tras una breve semblanza de la vida y obra de Francisco Acuyo (Granada, 1960), se presentan los veinticinco poemas que componen la antología y se ofrece la traducción en versión bilingüe de cuatro poemas de los libros de su primera época: La transfiguración de la lira (1984) y No la flor para la guerra (1987). Cierra el trabajo una bibliografía selecta del poeta.

Palabras clave: Francisco Acuyo, traducción poética, antología en portugués

Abstract: In this paper, our focus will be one translation project from Spanish to Portuguese regarding the poetic work of Francisco Acuyo (Granada, 1960).

The project takes the form of an anthology that will bring together 25 poems along with their translations. This paper begins with a short overview of the life and writings of Francisco Acuyo. Next, as an example, we present four original poems along with their translations. All of them are typical from the first period of Acuyo's works ( $\mathrm{La}$ transfiguración de la lira, 1984 and No la flor para la guerra, 1987). In the final section, we offer a select bibliography of his work.

Key words: Francisco Acuyo, poetic translation, poetic anthology in Portuguese

\section{Semblanza de Francisco Acuyo}

\subsection{Nota biográfica}

Francisco Acuyo Donaire nace en Granada el 17 de marzo de 1960. De sus primeros estudios, cabe resaltar los años que cursó el bachillerato en la Academia Fides de Granada, de especial relevancia para el autor, pues en ella empieza a manifestar su inclinación por las actividades literarias y sobre todo por la poesía, en lo que tuvo mucho que ver Carlos Villarreal, director y profesor de la academia. Posteriormente, cursó estudios de Derecho y de Teoría de la Literatura y Literatura Comparada, en esta 
última disciplina es doctor por la Universidad de Granada. En paralelo a su formación, realiza numerosas actividades de edición en publicaciones diversas: fue codirector de la revista literaria Extramuros junto a su fundador ya desaparecido, José Espada (y, poco después, su director), así como director de la colección literaria del mismo nombre durante esta época. Es asesor de la revista Papeles Mojados de Río Seco, de Sevilla; director de la revista Jizo de Humanidades y de las colecciones Jizo de Literatura para niños, de Literatura y Artes Plásticas y de Literatura Contemporánea, igualmente del sello editorial Jizo. Ha sido colaborador del Grupo de Investigación Interlingüística de la Facultad de Traducción e Interpretación de la Universidad de Granada. Es miembro investigador de la Fundación Internacional Artecittá, miembro de la Asociación Andaluza de Semiótica y del Grupo de Estudios Semióticos de la Universidad de Granada. Obtuvo los premios Pedro Bargueño de Poesía (1982), el Gabriel Celaya (1997) y el Tesorillo (1998). Ha sido traducido al inglés, francés y polaco. Se preparan traducciones de sus versos al portugués (de los que aquí se ofrece un adelanto) y al ruso.

\subsection{Claves de su obra poética \\ Cuando Antonio Carvajal comenta de Francisco Acuyo que es}

[...] autor de un mundo poético extremadamente singular y profundo, ofrece una producción lírica que puede considerarse como una de las más originales y exuberantes del panorama literario y poético español. Si bien se manifiesta en su ejercicio poético fuera de cualquier corriente literaria, asume la mejor tradición poética (española y extranjera, moderna y clásica) para verter poemas de un extraordinario rigor compositivo y de una inusitada versatilidad formal, manifiestas en su íntimo y vital compromiso con el impulso creativo que alienta el espíritu de la verdadera poesía y el arte del mejor y más penetrante quehacer poético, ${ }^{1}$

se refería sin duda a uno de los rasgos que garantizaban una de las características más singulares de su poesía: su originalidad, aunque paradójicamente enraizada en la tradición más selecta de las letras y de la poesía en lengua española, y desde luego también de otras lenguas, apuntando claros influjos de la tradición clásica latina y griega. Así, se reconoce deudor de poetas de lenguas como la francesa (Baudelaire, Verlaine, Valery), la inglesa (fundamentalmente Shakespeare, T.S. Eliot o Withman), la portuguesa (Camoens o Pessoa), la italiana (Dante o Petrarca) y de poetas españoles del Siglo de Oro (Garcilaso, Fray Luis de León, S.

\footnotetext{
${ }^{1}$ Carvajal, A.: Nota introductoria a la nueva edición del libro de Francisco Acuyo, Pan y leche para niños, Ediciones El torno Gráfico, 2010, p. 11.
} 
Juan de la Cruz, Luis de Góngora, Lope de Vega y Quevedo a la cabeza), y poetas de la modernidad como Rubén Darío, Juan Ramón Jiménez, Unamuno, Antonio Machado, y ya en pleno s. XX, Jorge Guillén, Vicente Aleixandre, Luis Cernuda o Federico García Lorca.

En cualquier caso el autor siempre se proclama poco receptivo para hablar de su obra y de sí mismo como poeta:

[...] cuando se le ofrece al autor mismo de una obra de creación la posibilidad de ejercer una labor interpretativa capaz, debe si no de establecer claves de lectura, sí, al menos, dilucidar por aproximación algunas de las señas de identidad significativas de la misma; pues sucede que todos aquellos signos vertidos para propiciar una guía de perplejos en su lectura pueden convertirse en una suerte de martirio o de tortura exegética ciertamente insufribles, así nos lo hace saber de forma expresa a los que tratamos de entrar en el complejo pero extremadamente rico domino de su mundo poético. ${ }^{2}$

Hubieron de encontrar eco en su obra y en su concepto de la poesía los estudios retóricos y métricos desde sus inicios latinos y en la riquísima tradición española y en la no menos importante de la modernidad. El rigorismo formal proviene del amplio conocimiento de este ámbito singular de estudio y del reconocimiento de su extraordinario impulso generador creativo, muy a pesar de lo que tendencias actuales de la poesía piensan, pues ven en su seguimiento y uso una atadura que imposibilita la libertad creadora; antes bien, Francisco Acuyo encuentra en sus fundamentos una plataforma inusitada para, precisamente, "liberar el espíritu en pos de la consecución verdaderamente original del poema". ${ }^{3}$ Así pues, el conocimiento de estos y otros instrumentos (el gramatical y sintáctico, por ejemplo) son esenciales para el buen hacer y entender del fenómeno artístico poético. De hecho, en algunos momentos aquel impulso netamente creador poético entronca con el que observa el matemático, sujeto a toda la severidad de su disciplina, y que, no obstante de su elaboración, muchas veces puramente abstracta, admite la posibilidad sorprendente de responder a la realidad física del mundo.

En sus dos estudios teóricos publicados hasta la fecha: Fundamentos de la proporción en lo diverso (2009), el cual versa sobre las relaciones y fundamentos de la métrica en el territorio poético desde una perspectiva netamente viva, integradora y dinámica; y Fisiología de un espejismo (2010), donde establece parámetros de estudio muy novedosos sobre el

\footnotetext{
${ }^{2}$ En los límites de lo posible: el espejo postmoderno, en Ancile, Blog del poeta Francisco Acuyo (franciscoacuyo.blogspot.com, septiembre 2010).

${ }^{3}$ Acuyo, F.: Fundamentos de la proporción en lo diverso, Granada, Jizo ediciones, 2009, p. 121.
} 
mundo de la retórica, centrándose sobre todo en aspectos trópicos particularmente descriptivos del funcionamiento del elemento retórico en poesía (la sinestesia, la metáfora y el símbolo), mantiene en ellos un carácter metodológico en su acercamiento al fenómeno poético que trasciende ampliamente los cánones de los estudios literarios y lingüísticos al uso, pues incluye herramientas de aproximación propias de las ciencias más duras: matemáticas, física, biología... Recojo algunas reflexiones al respecto de estas obras señaladas:

Rememoramos en virtud de aquella complejidad dinámica que nutre el verso, el concepto integrador que singulariza aún más su naturaleza, y que vendrá a imponerse incluso en los momentos de desvío del precepto métrico, y que los sistemas al uso que lo informan no son sino aproximaciones o descripciones estadísticas o numéricas de probabilidad. Sería también interesante, ahora como entonces, decir que estas líneas no se refieren tanto a un estudio estrictamente métrico, como a una especial aproximación material a la estructura en la configuración lingüística, gramatical y métrica del poema, en tanto que nos referimos siempre a aquellos rasgos genuinos que se reconocen en el fenómeno poético, entendido, eso sí, como un peculiar ejercicio creativo, pues es susceptible de singular reconocimiento epistemológico. ${ }^{4}$

Respecto a Fisiología de un espejismo comenta, centrándose en el fenómeno de la sinestesia poética:

[...] puede hablarse en poesía de una auténtica panestesia que ordena el caos de las sensaciones percibidas consciente e inconscientemente. La percepción en poesía no tiene una validez que signifique fisiológicamente, pues no implica definición de un topos que sitúe corporalmente una noción específica o puntual. El verso ofrece el tactus intimus ciceroniano. Puede no distinguirse toda la información externa del sentido (vista, oído, tacto, olfato y gusto), del sensus interno que cualifica, distingue, ordena y unifica.

También sucede que, en ocasiones, la expresión poética vierte, en alarde metafórico, el tropel de percepciones corporales para mostrar sus síntomas hiper o hipoestésicos. No sabemos si la fisiología del poema se hace expresa en nuestro cuerpo, o, si nuestra conciencia perceptiva vibra despersonalizada desde el cuerpo poético. Estos y otros sugerentes aspectos son los que puede el lector atento descubrir a lo largo de las sugestivas páginas que conforman esta "Fisiología de un Espejismo". ${ }^{5}$

${ }^{4}$ Ibídem, p. 173

${ }^{5}$ Acuyo, F.: Fisiología de un Espejismo, Granada, Artecittá ediciones (Fundación Internacional Artecittá), 2010, p. 47. 
En este sentido ha de reconocerse que el mundo poético reflejo en la praxis y en la teoría (poética) de Francisco Acuyo mantiene acaso un insólito y profundo influjo de la misma matemática y de las ciencias naturales (con la física y astrofísica a la cabeza). No será extraño encontrar incluso referencias expresas a personajes de la filosofía y de la ciencia en libros de poemas: véase, por ejemplo, Los principios del tigre (1997), donde se establecen epígrafes y dedicatorias a científicos y filósofos de la ciencia. También puede llevar insólitamente al ámbito poemático la misma praxis científica cuando dedica poemas íntegros a la experiencia, siempre excepcional para el autor, como es la observación astronómica: así, en el poemario Centinelas del sueño (2008) desfilan poemas basados de forma exclusiva en esas observaciones estelares, llevando a término descripciones detalladas de cuerpos celestes en un tono lírico altamente sugestivo y embelesador capaz de alcanzar cotas auténticamente hipnóticas para el lector interesado. Reflexiona el crítico José Fernández Dougnac al respecto:

No existe, en este sistema, disociación alguna entre Poesía y Ciencia. La Matemática, por ejemplo, entendida como «obra del pensamiento puro", se armoniza sin estridencia con lo lírico. Del mismo modo que, sin la Astronomía, de la que es Acuyo gran aficionado, no se explicaría la recurrente aparición de uno de los símbolos que abordaremos más delante: la noche. Y finalmente, la parte central de Los Principios del Tigre, titulada «El jardín de los filósofos», así como todo el libro, participa de un componente filosófico-científico que es lo que le da su auténtica razón de ser. Poesía y Filosofía, Poesía y Ciencia, e incluso Poesía y Música forman, por tanto, un todo compacto del que deriva otra realidad artística más trascendente que sólo fragua en el crisol incorpóreo del poema. 6

En el "Prólogo" de esa misma obra Rosa Navarro apuntaba:

No hay violencia en los confines con el blanco que limita el poema porque la palabra cobra en su espacio su más dulce sonoridad. «Libre el verso, y...» sus dos primeras palabras «Su ave» nos llevan a sí mismas pero otras ya, en esperado calambur: «su suave / rosa». Es uno de los elementos esenciales de toda la poesía de Francisco Acuyo: la suavísima armonía musical. Como dice Ovidio de Eco, en

\footnotetext{
${ }^{6}$ Fernández Dougnac, J.: "La lira transfigurada de Francisco Acuyo", en Anthologie Bilingue, traducción al francés: Joëlle Guatelli Tedeschi. Prólogo de Rosa Navarro Durán. Edición de José Fernández Dougnac. Granada, Colección Entrelenguas, Jizo ediciones y el Grupo de Investigación Interlingüística de la Facultad de Traducción e Interpretación de la Universidad de Granada, no 10, 2003, p. 30.
} 
ese verso que recoge el poeta como lema: «Un sonido es lo que vive en ella».

Para que viva en su poema la música, la suave sonoridad, escoge a veces los dos dibujos estróficos esenciales de nuestra tradición literaria: el soneto y el romance. Pero no mantiene siempre la dualidad que los configura, su carácter culto y popular. Francisco Acuyo es uno de los mejores romancistas actuales: puede escribir romances entrañables a niños, acentuando el ritmo que lleva dentro la estrofa, pero también sabe darle al octosílabo la misma trascendencia esencial que el endecasílabo calza. En sus versos están otros asumidos, recreados, como testimonio de su asunción de la tradición, de su voluntad de asentarse en ella. ${ }^{7}$

Ciertamente la dimensión sonora, fónica, acústica, musical del poema adquiere en esta obra poética una relevancia importante, por otra parte acorde con las exigencias a las que antes aludía respecto a la rigurosidad en la construcción formal del verso, pero no por una razón amparada al estricto formalismo que cabría inferirse de tal concepción poemática, sino porque esa trama estructural responde a la complejidad misma de la vida con la que Acuyo encuentra íntima e ineludiblemente relacionada con la poesía. El rasgo vital de todos sus poemas es una de las claves no solo de lectura y compresión de sus poemas, también una de las señas de identidad de su obra y de su poética.

Otro de los elementos centrales para entender lo que la poesía sea radica en la especial concepción del tiempo. "No hay más tiempo que el del verso, no hay más fluir que la armonía, no hay más pausa que la que marca el compás. Silencio y luz, mucha luz; fundidos en sinestesia constante la no palabra y la luminosidad que deslumbra; el vuelo del instante y el olvido: una continuidad eterna".8 El autor mismo hace una reflexión del tiempo (poético) en la observación y reflexión sobre unos poemas de Góngora cuando dice:

He aquí que el poeta, al fin, nos enfrenta con la realidad del tiempo que aparentemente todo lo cambia: a saber su ilusoria imagen dinámica. Este espléndido juego en paradoja con el que concluye el soneto sería cota suficiente para encaramar a nuestro poeta a lo más alto del empíreo parnasiano, mas, a mi modesto entender, no contento con tal hazaña, nos deja un sabor en sus conceptos, con el que paladeamos muy al gusto de nuestra época, la sensación insana del

\footnotetext{
${ }^{7}$ Ibídem, pp. 14 y 16.

${ }^{8}$ Ibídem, p. 18.
} 
fluir temporal, la cual invita a una reflexión, por otra parte, no sujeta a ningún tiempo. ${ }^{9}$

En esta apresada y urgente semblanza sobre la obra y mundo poético de Francisco Acuyo, parece lícito añadir otro influjo no bien reconocido por sectores de la crítica; me refiero al que proviene de su interés por la cultura, el arte, la literatura, la poesía y la filosofía oriental, sobre todo la china y japonesa. Así, en publicaciones diversas ha abundado sobre aspectos relacionados con estos temas siempre relacionados con su obra y concepción de la poesía. ${ }^{10}$

La poesía de Francisco Acuyo, en fin, se sitúa en unos parámetros donde la variabilidad de sus registros y la exuberancia de la temática que la inspira son cuando menos singulares, pues estos constituyen uno de los fundamentos de su rica realidad literaria, pero será también su misma profunda concepción del fenómeno poético la que exponga toda su producción en una suerte de dominio aparte del ámbito literario y poético de la actualidad, en este punto nos decía el mismo poeta:

[...] sobre la poesía y la palabra poética, que acaso sea la expresión poética la manifestación de la palabra que marque con mayores controversias ese espacio o distancia entre el lenguaje y el mundo fenoménico, pues llega a establecerse que ambos son del todo irreconciliables en la misma realidad.

Se extrema hasta tal punto la prodigiosa relación del lenguaje y, «eso» que consideramos realidad en la poesía, que aquello «pronunciado» se nos ofrece como la sustancia conjurada en lo más íntimo de su esencia: o, definitivamente, diríase que se aleja de la realidad, o de manera inusitada y prodigiosa, se diría crearla (o recrearla, acaso) sin saber si es nuevo o ya transfigurado aquello que de la realidad expresa.

De la palabra poética podía decirse que traspasa, o que trasciende, quizá, los atributos mismos de la palabra; es la «conciencia» que a través de la misma acción de la palabra nos avisa que no es esta la «cosa» de la cual hablamos. Su ejercicio enigmático ofrece un instrumento donde la «observación pura» es posible.

La poesía nos regala la palabra que es «sonido» y, a través de ella, nos advierte del espacio que es básico no sólo para oír: además para

\footnotetext{
${ }^{9}$ Carpe diem: al albur de unos versos de D. Luis de Góngora, en Ancile, Blog del poeta Francisco Acuyo (franciscoacuyo.blogspot.com, septiembre 2010).

${ }_{10}$ Pueden consultarse a este respecto en el blog antes citado de Francisco Acuyo diversos artículos sobre "Zen y poesía" y "Taoísmo", que reflejan bien el conocimiento de estos temas y la influencia en su poesía.
} 
deslizarse en el proceso de escuchar, el cual requiere (exige) una específica atención, lejos de la experiencia, la memoria, e incluso del conocimiento, sobre todo entendido (y observado) este en su vertiente lógico racional. Observa lo que está más allá del pensamiento en un proceso milagroso de simultaneidad, donde el que habla y el que escucha disuelven sus fronteras individuales; es la observación que carece del horizonte siempre alienante del ego. Originaria de esta quietud sería la belleza.

La poesía «existe» cuando el que escucha está ausente; es perseguir la huella no marcada en el espacio o el tiempo por el hombre. Si el saber exige duda, la poesía, aun no sabiendo, culmina en la verdad, que es certeza. Inescrutabilidad de la poesía que una y otra vez niega, porque no sabe definirse; acaso porque el contenido no tiene ninguna relevancia, porque el vacío de la conciencia poética, del no saber, será siempre nuevo, activo, lejos de las conclusiones, juicios y disciplina del concepto: será por eso indescriptible la poesía. Si se describe, eso no es lo descrito. Sólo aquello que sucede en su "vacío» es innombrable y nuevo y nunca visto. 11

Puede decirse a modo de conclusión que la poesía de Francisco Acuyo remite a un espacio donde el poeta tiende a encerrarse en un mundo de arte pura y de formas sin contenido, si por contenido entendemos la realidad más convencional, creando una verdad que brota de la perfección estilística que persigue.

\section{UNA ANTOLOGÍA EN PORTUGUÉS DE FRANCISCO ACUYO}

La antología que se prepara en portugués de la poesía de Francisco Acuyo recoge 25 poemas. La selección, que ha sido ajustada con el propio poeta, pretende ser representativa del mundo poético del autor de modo que el lector pueda tener un primer contacto, en versión bilingüe, con diferentes periodos de su obra. Los poemas seleccionados son los siguientes:

- De La transfiguración de la lira (1984): la cuarteta octosílaba "Libre el verso, y..." y el soneto "Finale".

- De No la flor para la guerra (1987): los romances "Romance del Avellano" y "Laberinto y planeta".

- De Ancile (1991): la estancia "December", primer poema incluido en una antología de ese poemario.

- De Cuadernos del Ángelus (1992): el soneto "Naufragio" y la estancia "Revelación de Narciso".

${ }^{11}$ Acuyo, Fisiología..., op. cit., p. 77. 
- De Vegetal contra mosaico (1994): las canciones en arte menor de carácter aforístico que componen "Tempo".

- De Los principios del Tigre (1997): el romance "A la sombra del álamo blanco" y el soneto "Amor: un gesto que cae".

- De Mal de lujo (1998): los sonetos "El rostro del amor", "Distancia de amor" y "Consenso"; y el poema en verso libre "Lo que yo siento".

- De Pan y leche para niños (2000): los romances en heptasílabos "El hada de mi niño" y "El sueño de Paula".

- De El hemisferio infinito (2003): el poema "Transformación y sacrificio" que combina versos heptasílabos, eneasílabos y endecasílabos; la décima "Cauce del tiempo", el romance "Un instante en el templete de los Leones" y "La silueta de Tiresias".

- De Centinelas del sueño (2008): la décima "Géminis", el soneto "Amigos en la noche" y el romance "Carmen Constelado".

- De Diez décimas decimales (2000, $2^{\mathrm{a}}$ ed. aumentada 2009): "Con sagrado color" y la inédita "La enésima décima decimal".

La selección de poemas presentados para la ocasión exponen, no sin dificultad, una semblanza de la obra poética de Francisco Acuyo; buena parte de esta dificultad radica en el hecho de la unidad incuestionable que constituye cada uno de los libros que integran el corpus de su poesía hasta el punto de que en las diferentes antologías vertidas de su poemas (en francés, inglés o polaco, que se recogen en la bibliografía final) no se han incluido poemas de algunos de sus libros, por ejemplo del titulado Ancile. Sin embargo, en esta ocasión el propio autor ha considerado pertinente ofrecer la estancia "December" de ese libro, que abre el periodo de los años noventa, para reforzar el criterio adoptado en esta antología que no es otro sino el de dar una visión global, aunque no exhaustiva, de su obra.

De las dificultades obvias de la traducción de la poesía de Acuyo a otras lenguas han dado buena cuenta los traductores en sus respectivas antologías. En el caso de esta antología en lengua portuguesa, a las dificultades propias del traducir poesía y, en concreto, a las más específicas de la traducción de una poesía como la de nuestro autor, se añade la cercanía lingüística entre español y portugués que exige estar en constante alerta ante la amenaza de la interferencia. Por otro lado, es cierto que en relación con otras lenguas más alejadas, la proximidad entre portugués y español permite una aproximación más literal, que he pretendido sea la guía de mi versión, sin dejar de respetar la musicalidad y, en la medida de lo posible, el metro de la poesía de Acuyo.

Además, es una gran suerte contar con la ayuda del propio poeta para solventar las dudas que surgen en el proceso de traducción; así, puedo afirmar que han sido constantes las consultas en relación con el uso 
sintáctico, cuando menos peculiar, en no pocos momentos de sus versos; igualmente ha sido fundamental las orientaciones que me proporcionó sobre la cuestión métrica, tan importante para una aproximación correcta a sus poemas, pero no tan decisiva como en el caso comentado de lenguas más alejadas para lo que hubo de buscarse los metros más convenientes en la lengua de inversión del poema y que no tenían por qué corresponder con la equivalencia estricta española (así ocurrió con la edición francesa e inglesa de sus versos, en las que se adecuaron los parámetros métricos más oportunos para su adecuada interpretación). En cambio, en el caso de la versión en portugués es posible mantener los mismos metros usados por Acuyo (en especial, cabe destacar el uso no solo del verso endecasílabo, sino el del octosílabo aplicado a los numerosos romances de su obra).

\section{CuATRO POEMAS EN VERSIÓN BILINGÜE}

Los cuatro poemas seleccionados son una muestra de la antología proyectada. Los poemas pertenecen a los dos primeros libros de Francisco Acuyo donde pueden verse ya muchos de los elementos característicos de su poesía:

- De La transfiguración de la lira (1984): la cuarteta octosílaba "Libre el verso, y..." y el soneto "Finale".

- De No la flor para la guerra (1987): los romances "Romance del Avellano" y "Laberinto y planeta".

Estos poemas son también buenos ejemplos del gusto por la métrica tradicional (octosílabo y endecasílabo) que se encarna en su predilección por el romance y el soneto. En la traducción me he esmerado en armonizar la literalidad con la musicalidad propia de la poesía de Acuyo por lo que he procurado mantener tanto el metro como el ritmo en portugués siempre que no desvirtuase el texto original. 
LA TRANSFIGURACIÓN DE LA LIRA (1984)

LIBRE EL VERSO, Y...

SU ave al viento y silenciosa, no expresa la voz su suave

rosa, que apenas si sabe

no más de su voz, la rosa. 


\section{A TRANSFIGURAÇÃO DA LIRA (1984)}

\section{LIVRE O VERSO, E...}

SU' ave ao vento e silenciosa,

não expressa a voz a sua suave

rosa, que pouco mais sabe

ela de sua voz, a rosa. 


\section{FINALE}

DEL ángel soy naufragio de la ciencia que a luz de mi reflejo suspendido -aunque poeta, referidlo os pidotendrá matiz espejo toda esencia.

¡Cuánta los dulces términos ausencia demuestra tanto coro trascendido! desmayo abajo viendo que han subido la luz y el alma, el aire y la conciencia.

A la luz donde duermo no escondida, un ramo me recuerda destilado en el vaso profundo de la vida.

Concentro en él mi ardor, y en él me inspiro: y de la esencia púrpura turbado se elevan los aromas, y suspiro. 
FINALE

DAQUELE anjo sou naufrágio da ciência que ao lume do meu reflexo suspenso - embora poeta, dizê-lo vos peço terá matiz espelho toda a essência.

Quanta os docíssimos termos da ausência demonstra tanto coro transcendido! desmaio em baixo observando ascendidos a luz e o impulso, o ar e a consciência.

À luz onde adormeço não escondida, um buquê me recorda destilado dentro do copo profundo da vida.

Nele meu ardor centro, nele me inspiro: e dessa essência púrpura turvado recendem os aromas, e eu suspiro. 
NO LA FLOR PARA LA GUERRA

(1987, 2ª edición aumentada 1997)

ROMANCE DEL AVELLANO*

LAS hojas vierten destellos y pájaros enlazados que mueven entre las rosas el aire tibio y los ramos.

Del árbol nudos deshecha la fuente del avellano. y en senda de ruiseñores distiende el cáliz extraño:

Ya conmueve los zarzales de cristales y despacio, transfigura con el agua en espinas su descanso.

Triste de risas celestes -murmura pálido un nardoel agua flores deshace entre los senos de mármol.

Aquellos dedos de plata un lirio casi han tomado, por sus hojas cristalino y sus pétalos sonámbulo.

Rosa blanca es blanca rosa en el agua:

Yo te guardo

en la mano, y la corola guarda, tuya, mi otra mano.

Traigo luces tibiamente, y un deseo limpio traigo. Mostraba con brisa tenue la luz nocturna su claustro.

Despiértenme mariposas. Palomas sueltas el ramo. 
NÃO A FLOR PARA A GUERRA

(1987, 2ª edição acrescida 1997)

\section{ROMANCE DA AVELANEIRA}

AS folhas vertem lampejos e pássaros enlaçados que agitam por entre as rosas o tépido ar e os ramos.

Desta árvore nós desfeita a fonte da avelaneira, e em senda de rouxinóis distende o cálice estranho:

E já comove os silvados de cristais e devagar, e transfigura com a água em espinhos seu descanso.

Triste de risos celestes - murmura pálido um nardo as águas flores desfazem entre os seios de mármore.

Aqueles dedos de prata um lírio quase prenderam, por suas folhas cristalino, por suas pétalas sonâmbulo.

Rosa branca é branca rosa na água:

na mão, e a corola

$$
\text { Eu te guardo }
$$

tua guarda a minha outra mão.

Trago luzes tepidamente, e um desejo limpo trago. Mostrava com brisa ténue a luz nocturna seu claustro.

Acordem-me borboletas. Pombas soltas no ramo. 
La rosa mueve a la rosa

y el aire apenas el tallo.

La mano finge del viento

el silbo suave llevando,

del llanto perlas al sueño,

del sueño perlas al Ilanto.

* Fuente de Granada 
A rosa balança a rosa,

e o ar apenas o talo.

A mão simula do vento

o silvo suave levando,

do pranto pér'las ao sonho,

do sonho pér'las ao pranto.

Hikma 9 (2010), 209-231 


\title{
LABERINTO Y PLANETA
}

\author{
AMBIGÜEDAD esencial, \\ no dejaste alguna seña. \\ Difícilmente abandona \\ el lugar lo que tan cerca
}

del origen nos habita en la fruición de la piedra, o ese ciervo decisivo entre las flores de estética;

así mismo nos explica, el discurso y la vivencia al beber del fresco arroyo que no supo nunca de épocas,

que discurre entre cristales todavía y entre arenas, y sobre aquella colina en verdad se manifiesta.

Amor que todo lo alcanza no contiene donde empieza el bosque, el astro, la flor: La nada todo lo hereda.

Este juego no es muy serio. El poeta no es el poeta, mas el poeta, sin embargo, fundió de toda materia

con su celeste albedrío del espíritu la arena, y sobre el mar nos aguarda todo cubierto de estrellas.

Transitoria luz y tibia deslizaron para el poeta entonces miles de historias: y el hombre habitó en la tierra. 


\section{LABIRINTO E PLANETA}

AMBIGUIDADE essencial, não deixaste algum sinal.

Dificilmente abandona

o lugar o que tão perto

da origem nos habita

na fruição da pedra,

ou esse cervo decisivo

entre as flores da estética:

é assim que nos explica,

o discurso e a vivência

bebendo do fresco arroio

que nunca conheceu épocas,

que discorre entre cristais

ainda e entre as areias

e por cima da colina

com verdade se manifesta.

Amor que tudo alcança

não contém onde começa

o bosque, o astro, a flor:

O nada tudo herda.

Este jogo não é mui sério.

O poeta não é o poeta,

mas o poeta, porém,

fundiu de toda a matéria

com seu celeste alvedrio do espírito a areia,

e sobre o mar nos aguarda coberto todo de estrelas.

Transitória luz e tépida deslizaram ao poeta

então milhares de histórias

e o homem habitou a terra. 


\section{BIBLIOGRAFÍA SELECTA DE FRANCISCO ACUYO}

Libros de poesía

La transfiguración de la lira. Granada, 1aㅡ entrega de la colección Trames de Poesía, no 2, (dirigida por Carlos Villareal), edita librería Al-Andalus, 1984, 32

p. No la flor para la guerra. Granada, Pliegos de vez en cuando, tercer suplemento, viñeta de Miguel Rodríguez Acosta, edición al cuidado de Antonio Carvajal, 1a edición, 1987, 77 p.

Ancile. Alicante, Aguaclara, colección Anaquel de Poesía, $\mathrm{n}^{\circ}$ 15, ilustraciones y portada Salvador Fajardo Contreras, 1991, 64 p.

Cuadernos del Ángelus. Granada, Diputación Provincial de Granada, Colección Genil de Literatura, no 5, 1992, 80 p.

Vegetal contra mosaico. Valladolid, Diputación Provincial de Valladolid, Centro de Creación y Estudios Literarios, Fundación Jorge Guillén, 1994, 56 p.

No la flor para la guerra. Granada, Extramuros, $2^{a}$ edición con un prólogo y cuatro inéditos (prólogo de Antonio Carvajal), edición numerada, nํㅜ 1, 1997, $110 \mathrm{p}$.

Los principios del tigre. Torredonjimeno (Jaén), V Certamen Internacional de Poesía Gabriel Celaya, prólogo Rosa Navarro Durán, 1997, 76 p.

Mal de lujo. Madrid, ediciones Caroal, colección Isis de Poesía, nº 1, portada de Salvador Fajardo Contreras, 1998, 128 p.

Pan y leche para niños, Granada, Ediciones Método. Jizo de Literatura para niños, $n^{0}$ 1, ilustraciones de $M^{a}$ a Jesús López Alonso y Salvador Fajardo, 2000, 94 p.

El hemisferio infinito. Sevilla, editorial Point de Lunettes, Colección Cría Cuervos, no 4, prólogo de Rosa Navarro Durán, 2003, 88 p.

Centinelas del sueño. Benalmádena (Málaga), Ediciones de Aquí, Colección el pie de la letra, (Poesía), no XI, Prólogo de Manuel Mantero, 2008, $57 \mathrm{p}$.

Antologías

Bilingual Anthology. Traducción al inglés: José Luis Vázquez Marruecos y Esther Vázquez del Árbol. Prólogo de Rosa Navarro Durán. Edición de José Fernández Dougnac. Granada, Colección Entrelenguas. nº 7, Método Ediciones y el Grupo de Investigación Interlingüística de la Facultad de Traducción e Interpretación de la Universidad de Granada, 2002, 160 p.

Anthologie Bilingue. Traducción al francés: Joëlle Guatelli Tedeschi. Prólogo de Rosa Navarro Durán. Edición de José Fernández Dougnac. Granada, Colección Entrelenguas, Jizo ediciones y el Grupo de 
Investigación Interlingüística de la Facultad de Traducción e Interpretación de la Universidad de Granada, № 10, 2003, 203 p.

Ilez dlugich sierpni, Antologia poetów Grenady. Cracovia, Instytut filologii Romanskiejej Uj, 2010. (Traducción al polaco de una selección de versos de Francisco Acuyo.)

De la métrica celeste: antología poética (1984-2003). Prólogo de Rosa Navarro Durán. Selección y notas de José Ignacio Fernández Dougnac. Salobreña (Granada), Edt. Alhulia. Colección Palabras Mayores (Poesía), no 34, 2007, 200 p.

\section{Cuadernos}

Diez décimas decimales. Jizo ediciones, colección Jizo de Literatura y Artes Plásticas, $\mathrm{n}^{\circ}$ 1, (con un CD multimedia con poemas y obra gráfica), edición bilingüe español-inglés, con grabados de $\mathrm{M}^{\mathrm{a}}$ José de Córdoba, para la World Fine Art Gallery de Nueva York, 2000, 50 p.

El arte del tiempo. Jizo ediciones, colección Jizo de Literatura y Artes Plásticas, $n^{\circ}$ 2, (con un CD multimedia con poemas y obra gráfica), edición bilingüe español-inglés, con reproducciones de óleos de Emilio Peregrina, para la exposición la Casa de la Cultura de la ciudad de Albolote (Granada), 2000, 50 p.

Ángel contrario al imposible. Jizo ediciones, colección Jizo de Literatura y Artes Plásticas, no 3, (con un CD multimedia con poemas y obra gráfica), edición bilingüe español-francés, con reproducciones de obra gráfica y objetos artísticos de Javier Seco Goñi, para la exposición en el Colegio de España en París, 2001, 50 p.

De la línea y su espejismo. Jizo ediciones, colección Jizo de Literatura y Artes Plásticas, no 4, (con un CD multimedia con poemas y obra gráfica), con reproducciones de pinturas de Salvador Fajardo, para la exposición en la Casa Cultura de Albolote (Granada), 2001, 34 p.

En campos de zafiro. Jizo ediciones, colección Jizo de Literatura y Artes Plásticas, $n^{\circ} 5$, (con un CD multimedia con poemas y obra gráfica), con un poema introductorio de Antonio Carvajal y reproducciones de pinturas de Mํㅡㄹ Teresa Martín Vivaldi, para la exposición en la Galería Euroarte de Lisboa, 2001, 34 p.

El jardín de los espíritus. Jizo ediciones, colección Jizo de Literatura y Artes Plásticas, ํo 6, (con un CD multimedia con poemas y obra gráfica), con reproducciones de pinturas de $M^{\underline{a}}$ Teresa Martín Vivaldi, para la exposición en la galería Daimler-Chrysler A.G., Niederlassung (Friburgo), 2001, $34 \mathrm{p}$.

Zeitgeist (o el espíritu del tiempo). Jizo ediciones, colección Jizo de Literatura y Artes Plásticas, № 7, (con un CD multimedia con poemas y obra gráfica), con reproducciones de pinturas de Emilio Peregrina, 
para la exposición en la galería del llustre Colegio de Farmacéuticos de Granada, 2008, 24 p.

Diez décimas decimales ( $2^{\mathrm{a}}$ edición). Jizo ediciones, colección Jizo de Literatura y Artes Plásticas, $n^{\circ}$ 8, (con un CD multimedia con poemas y obra gráfica), con reproducciones de pinturas de $\mathrm{M}^{\mathrm{a}}$ - José de Córdoba, con motivo del Tercer Congreso Internacional de Sinestesia, Ciencia y Arte celebrado en el Parque de las Ciencias de Granada, y de la concesión de la Medalla al Mérito Artístico a dicha autora, 2009, $40 \mathrm{p}$.

\section{Estudios sobre Poesía}

Los fundamentos de la proporción en lo diverso: sobre la simetría y la asimetría endecasilábica (tesis doctoral). Granada, Departamento de Lingüística y Teoría de la Literatura y Literatura Comparada, Universidad de Granada, 2007, 374 p.

Fundamentos de la proporción en lo diverso. Nueva edición corregida y adaptada. Granada, Jizo ediciones, de Ensayo, no 17, 2009, 427 p.

Fisiología de un espejismo. Granada, Artecittá ediciones (Fundación Internacional Artecittá), 2010, 140 p. 
